\title{
PENGARUH SIKAP MENTAL, LINGKUNGAN KERJA DAN PENGHASILAN TERHADAP PRODUKTIVITAS KARYAWAN PT. UNGGUL WIDYA TEKNOLOGI LESTARI KABUPATEN MAMUJU UTARA.
}

\author{
Oleh : \\ Megawaty Sangkota \\ (Dosen Fakultas Ekonomi Universitas Alkhairaat)
}

\begin{abstract}
ABSTRAK
Penelitian ini mengungkapkan Pengaruh Sikap Mental, Lingkungan Kerja dan Penghasilan berpengaruh serempak terhadap Produktivitas Karyawan PT. Unggul Widya Teknologi Lestari Kabupaten Mamuju Utara. Tujuan yang ingin dicapai dalam penelitian ini Untuk mengetahui Pengaruh Sikap Mental, Lingkungan Kerja dan Penghasilan berpengaruh serempak terhadap Produktivitas Karyawan PT. Unggul Widya Teknologi Lestari Kabupaten Mamuju Utara. Metode yang digunakan Penelilti bersifat Deskriptif dengan alat bantu koesioner terhadap 38 responden. Hasil penelitian ini membuktikan bahwa melihat pengaruh variabel sikap mental, lingkungan kerja, dan penghasilan terhadap produktivitas karyawan sebesar 63,2\% artinya pengaruh variabel bebas (independen) terhadap variabel terikat (dependen). Sedangkan sisanya 36,8\% adalah pengaruh variabel lain yang tidak diteliti dalam penelitian ini.
\end{abstract}

Kata Kunci: Produktivitas, Sikap Mental, Lingkungan Kerja dan Penghasilan.

\section{LATAR BELAKANG}

Menurut (Umar A, 2019) Tujuan didirikannya perusahaan adalah untuk mencari keuntungan yang layak untuk memelihara dan mempertahankan kelangsungan hidup perusahaan serta mengembangkan usaha. PT. Unggul Widya Teknologi Lestari Kabupaten Mamuju Utara merupakan perusahaan yang bergerak pada pengelolaan kepala sawit menuntut karyawan untuk meningkatkan produktivitas kerjanya sehingga segala tujuan perusahaan dapat tercapai dengan efektif dan efisien. Bagi karyawan, setiap kebutuhan yang diperlukan akan menjadi motivasi bagi karyawan untuk meningkatkan produktivitas kerjanya. Menurut (Salim, 2019) Faktor penentu dalam kelangsungan hidup suatu industri adalah faktor karyawan. Karyawan yang memiliki sikap mental yang baik dalam melaksanakan pekerjaannya tentunya akan membantu perusahaan dalam mencapai kemajuan karena sikap adalah kondisi mental dan neural yang diperoleh dari pengalaman, yang mengarahkan dan secara dinamis mempengaruhi respon-respon individu terhadap semua objek dan situasi yang terkait. Dengan kondisi sikap mental karyawan tentunya dapat meningkatkan produktivitas kerjanya. Apalagi ditunjang dengan lingkungan kerja yang baik di mana lingkungan kerja merupakan keadaan sekitar tempat kerja baik secara fisik maupun non fisik yang dapat memberikan kesan yang menyenangkan, mengamankan, menentramkan, dan betah kerja hal ini tentunya akan meningkatkan produktivitas kerja karyawan. Dengan peningkatan produktivitas kerja karyawan tentunya akan berpengaruh pula pada tingkat penghasilan karyawan tersebut. Menurut (Rahman, 2019) lingkungan kerja juga merupakan salah satu faktor yang menyebabkan peningkatan produktivitas karyawan.

Karyawan PT. Unggul Widya Teknologi Lestari Kabupaten Mamuju Utara selalu berusaha menjalankan tangung jawab kerjanya dengan baik dan benar sehingga dapat meminimalisir kesalahan kerja, namun ada saja permasalahan yang timbul dalam melaksanakan pekerjaan di mana sering terjadi kesalahan komunikasi antara masing-masing bidang kerja yang mengakibatkan 
lingkungan kerja yang kurang kondusif serta masih banyaknya karyawan yang belum terlalu memahami tugas yang diberikan perusahaan dengan baik dan masih banyak juga karyawan yang kurang disiplin kerja akhirnya berimbas pada produktivitas kerja karyawan. Selain itu pula masih banyak karyawan yang memiliki tingkat pendidikan rendah sehingga mengakibatkan banyaknya karyawan yang kurang memahami bidang kerjanya, kurangnya tangung jawab karyawan atar pekerjaannya sehingga banyak pekerjaan yang tidak terselesaikan tepat waktu. Hal ini mungkin di akibatkan oleh tingkat pendapatan yang relatif rendah sehingga berdampak pula pada produktivitas kerja karyawan. Hal ini yang harus diperhatikan oleh pimpinan PT. Unggul Widya Teknologi Lestari Kabupaten Mamuju Utara sehingga tujuan perusahaan dapat berjalan secara efektif dan efisien.

Berdasarkan uraian di atas, menjelaskan bahwa sikap mental, lingkungan kerja dan tingkat pendapataan berhubungan erat dengan produktivitas karyawan, maka penulis tertarik untuk melakukan penelitian mengambil judul: “ Pengaruh Sikap Mental, Lingkungan Kerja dan Penghasilan Terhadap Produktivitas Karyawan PT. Unggul Widya Teknologi Lestari Kabupaten Mamuju Utara".

\section{Rumusan Masalah}

Berdasarkan latar belakang di atas, maka permasalahan dalam penelitian ini adalah:

1. Apakah Sikap Mental, Lingkungan Kerja dan Penghasilan berpengaruh serempak terhadap Produktivitas Karyawan PT. Unggul Widya Teknologi Lestari Kabupaten Mamuju Utara?

2. Apakah Sikap Mental berpengaruh terhadap Produktivitas Karyawan PT. Unggul Widya Teknologi Lestari Kabupaten Mamuju Utara?

3. Apakah Lingkungan Kerja berpengaruh terhadap Produktivitas Karyawan PT. Unggul Widya Teknologi Lestari Kabupaten Mamuju Utara?

4. Apakah Penghasilan berpengaruh terhadap Produktivitas Karyawan PT. Unggul Widya Teknologi Lestari Kabupaten Mamuju Utara?

\section{Tujuan Penelitian}

sebagai berikut:

Adapun Tujuan Penlitian ini adalah

1. Untuk mengetahui dan menganalisis Sikap Mental, Lingkungan Kerja dan Penghasilan berpengaruh serempak terhadap Produktivitas Karyawan PT. Unggul Widya Teknologi Lestari Kabupaten Mamuju Utara.

2. Untuk mengetahui dan menganalisis Sikap Mental berpengaruh terhadap Produktivitas Karyawan PT. Unggul Widya Teknologi Lestari Kabupaten Mamuju Utara.

3. Untuk mengetahui dan menganalisis Lingkungan Kerja berpengaruh terhadap Produktivitas Karyawan PT. Unggul Widya Teknologi Lestari Kabupaten Mamuju Utara.

4. Untuk mengetahui dan menganalisis penghasilan berpengaruh terhadap Produktivitas Karyawan PT. Unggul Widya Teknologi Lestari Kabupaten Mamuju Utara.

\section{METODE PENELITIAN}

Penelitian ini dilakukan untuk menjelaskan pengaruh dan gejalah variabel yang diteliti, di mana peneliti secara langsung ke objek penelitian untuk melakukan pengamatan dan menganalisis Produktivitas Karyawan PT. Unggul Widya Teknologi Lestari Kabupaten Mamuju Utara. Dalam pelaksanaan penelitian ini akan digunakan tipe penelitian deskriftif penelitian deskriftif yaitu jenis penelitian yang bertujuan untuk menggambarkan, menjelaskan keadaan yang ada di perusahaan berdasarkan fakta dan data yang dikumpulkan kemudian disusun secara sistematis dan untuk menguji hubungan antar variabel yang diteliti dalam bentuk pengujian. (Sugiyono; 2009). Lokasi penelitian ini dilakukan pada PT. Unggul Widya Teknologi Lestari Dusun Bulili Raya Desa Motu Kecamatan Baras Kabupaten Mamuju Utara Provinsi Sulawesi Barat, Waktu penelitian ini dilakukan pada Juni Oktober 2019.

Populasi adalah wilayah generalisasi yang terdiri dari objek atau subjek yang mempunyai kualitas dan karakteristik tertentu yang ditetapkan oleh peneliti untuk dipelajari dan kemudian ditarik kesimpulannya (Sugiyono, 2010; 115). Dalam penelitian ini populasinya adalah seluruh karyawan PT. Unggul Widya Teknologi Lestari Kabupaten Mamuju Utara yang berjumlah 60 orang karyawan tetap yang telah mendapatkan surat keputusan sebagai karyawan tetap dan bekerja pada kantor PT. Unggul Widya Teknologi Lestari Kabupaten Mamuju Utara. Setelah dilakukan penarikan sampel menggunakan rumus slovin diperoleh sampel sebanyak 38 responden.

\section{Hasil Penelitian.}


Uji Asumsi Klasik

Sebelum melakukan analisis regresi, agar perkiraan menjadi tidak bias, maka dilakukan beberapa uji asumsi klasik yang harus dipenuhi:

Uji Normalitas

Tujuan uji normalitas adalah untuk mengetahui apakah distribusi sebuah data mengikuti atau mendekati distribusi normal.Uji normalitas bertujuan untuk menguji apakah model regresi berdistribusi normal.Uji normalitas dapat dilakukan dengan analisis grafik dilihat dari titiktitik yang menyebar disekitar garis diagonal yakni distribusi data dengan bentuk lonceng dan distribusi data tersebut tidak menceng ke kiri atau menceng ke kanan.Uji normalitas dilakukan dengan mengunakan pendekatan kolmogorv sminorv. Dengan mengunakan tingkat signifikan 5\% (0,05) maka jika nilai Asymp.Sig. (2-tailed) diatas nilai signifikan $5 \%$ artinya variabel residual berdistribusi normal.

\section{Gambar 1}

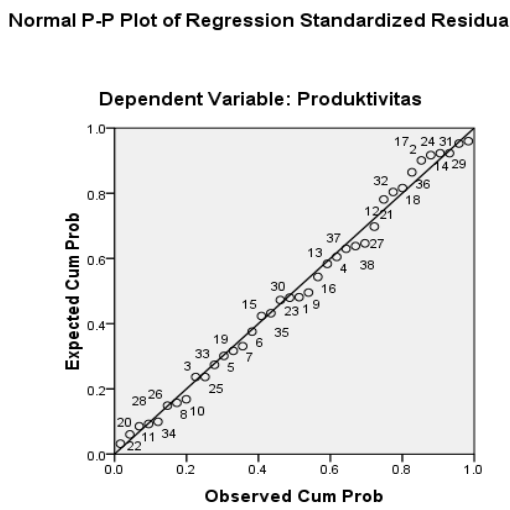

Gambar 1: Pengujian Normalitas P-P Plot

Uji Heteroskedastisitas

Model regresi yang baik adalah yang tidak terjadiHeteroskedastisitas.Untuk menguji

Heteroskedastisitas dilakukan dengan analisis grafik.Melalui analisis grafik suatu model regresi diangap tidak terjadi Heteroskedastisitas jika titiktitik menyebar secara acak dan tidak membentuk suatu pola tertentu yang jelas serta tersebar di atas maupun dibawah angka nol pada sumbu $\mathrm{Y}$.

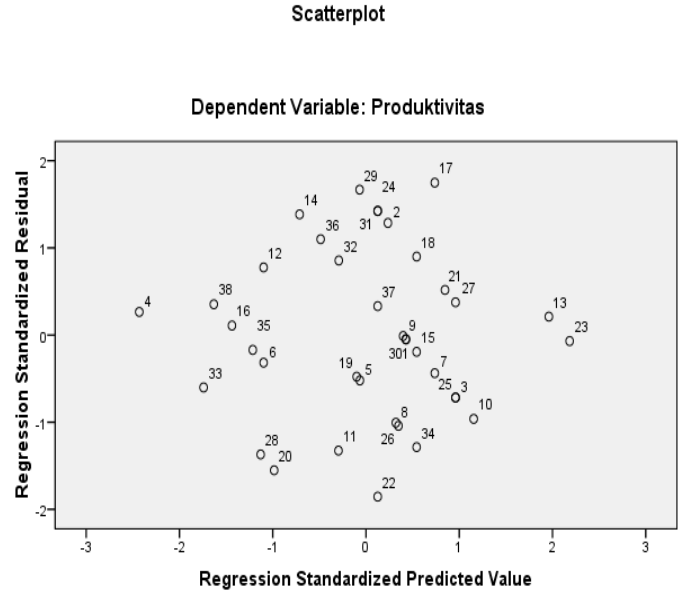

Gambar 2: Pengujian Heteroskedastisitas Scatterplot.

Gambar 2 memperlihatkan titik-titik menyebar secara acak dan tidak suatu pola tertentu yang jelas serta baik di atas maupun di bawah angka nol pada sumbu Y. Hal ini berarti tidak terjadi Heteroskedastisitas pada model regresi, sehingga model regresi layak dipakai untuk memprediksi prestasi kerja berdasarkan masukkan variabel independennya.

\section{Analisis Regresi Linear Berganda}

Analisis regresi linear berganda dalam penelitian ini digunakan untuk mengetahui pengaruh faktor sikap mental (X1), lingkungan kerja (X2), dan penghasilan (X3) terhadap produktivitas karyawan PT. Unggul Widya Teknologi Lestari Kabupaten Mamuju Utara berdasarkan pengujian diperoleh hasil sebagai berikut:

Tabel 1

Hasil Pengujian Regresi Linear Berganda Faktor Terikat $=$ Produktivitas Karyawan $(\mathrm{Y})$

\begin{tabular}{|l|r|r|r|}
\hline \multicolumn{1}{|c|}{ Variabel } & \multicolumn{1}{|c|}{ Beta } & t-hit & \multicolumn{1}{c|}{ Sig.t } \\
\hline (Constant) & 2.530 & 1.057 & .298 \\
Sikap Mental & .350 & 2.154 & .038 \\
Lingkungan Kerja & .480 & 3.470 & .001 \\
Penghasilan & .703 & 5.836 & .000 \\
\hline $\mathrm{n}=38$ & \\
Konstanta = 2.530 & \\
Koefesien Korelasi $(\mathrm{R})=0,795$ \\
Koefisien Determinasi $\left(\mathrm{R}^{2}\right)=0,632$ \\
F-Statistik = 19.471 \\
Sig.F =0,000 \\
\hline
\end{tabular}

Sumber: Data Primer Diolah 
Dari hasil pengujian dengan menggunakan regresi linier berganda di atas, maka dapat disusun persamaan regresi berganda dari pengaruh sikap mental (X1), lingkungan kerja (X2), dan tingkat penghasilan (X3) terhadap produktivitas karyawan PT. Unggul Widya Teknologi Lestari Kabupaten Mamuju Utara yaitu:

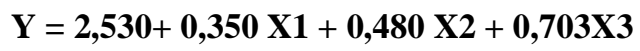

Hasil pengujian di atas menunjukan, di mana nilai konstanta 2,530 merupakan bilangan tepat yang berarti terjadi pengaruh sikap mental (X1), lingkungan kerja (X2), dan tingkat penghasilan (X3) terhadap produktivitas karyawan PT. Unggul Widya Teknologi Lestari Kabupaten Mamuju Utara yaitu 2,530.

Selanjutnya koefisien regresi faktor sikap mental (X1) sebesar 0,350 memberikan arti bahwa jika terjadi perubahan X1 sebesar satu satuan maka produktivitas karyawan akan terjadi pula, perubahan terhadap produktivitas karyawan PT. Unggul Widya Teknologi Lestari Kabupaten Mamuju Utara sebesar 0,350 dengan asumsi variabel lain diangap konstan terjadi pengaruh sebesar 0,350 atau $35 \%$ terhadap produktivitas karyawan. Koefesien regresi faktor lingkungan kerja memberikan arti bahwa terjadi pengaruh sebesar 0,480 atau $48 \%$ terhadap produktivitas karyawan. Koefesien regresi faktor penghasilan memberikan arti bahwa terjadi pengaruh sebesar 0,703 atau $70,3 \%$ terhadap produktivitas karyawan PT. Unggul Widya Teknologi Lestari Kabupaten Mamuju Utara.

Multiple atau koefisien korelasi (R) adalah hubungan antara ketiga variabel bebas yaitu sikap mental, lingkungan kerja, dan tingkat penghasilan terhadap produktivitas karyawan PT. Unggul Widya Teknologi Lestari Kabupaten Mamuju Utara sebesar 0,795 artinya hubungan variabel bebas (independen) terhadap variabel terikat (dependen) adalah Kuat.

R Square atau koefisien determinasi $\left(\mathrm{R}^{2}\right)$ adalah melihat pengaruh antara variabel sikap mental, lingkungan kerja, dan tingkat penghasilan terhadap produktivitas karyawan sebesar 63,2\% artinya pengaruh variabel bebas (independen) terhadap variabel terikat (dependen). Sedangkan sisanya $36,8 \%$ adalah pengaruh variabel lain yang tidak diteliti dalam penelitian ini.

\section{Pembuktian Hipotesis}

a. Pembuktian Hipotesis Pertama

Hipotesis pertama yaitu pengaruh sikap mental, lingkungan kerja, dan tingkat penghasilan terhadap produktivitas karyawan PT. Unggul Widya Teknologi Lestari Kabupaten Mamuju Utara. Pembuktian hipotesis pertama mengguanakan uji $F_{\text {sig. Nilai signifikansi } 0,000<}$ $\alpha 0,05$. Maka terbukti ketiga variabel bebas yaitu sikap mental, lingkungan kerja, dan tingkat penghasilan berpengaruh secara serempak terhadap produktivitas karyawan PT. Unggul Widya Teknologi Lestari Kabupaten Mamuju Utara.

Dengan hasil penelitian ini maka diambil keputusan yaitu menolak Ho dan menerima H1 atau dengan kata lain hipotesis pertama dalam penelitian ini telah terbukti dan dapat diterima.

b. Pembuktian Hipotesis Kedua

Hipotesis kedua yaitu untuk mengetahui apakah variabel sikap mental (X1), secara parsial berpengaruh signifikan terhadap produktivitas karyawan PT. Unggul Widya Teknologi Lestari Kabupaten Mamuju Utara.

Dari tabel 4.7 diatas bahwa besarnya probabilitas signifikansi variabel sikap mental (X1) adalah $0,038<$ taraf signifikan yang diisyaratkan $\alpha$ 0,05. Dengan demikian bahwa secara statistik variabel sikap mental dalam penelitian ini memberikan pengaruh yang signifikan terhadap produktivitas karyawan PT. Unggul Widya Teknologi Lestari Kabupaten Mamuju Utara.

c. Pembuktian Hipotesis Ketiga

Hipotesis ketiga yaitu untuk mengetahui apakah variabel lingkungan kerja (X2), secara parsial berpengaruh signifikan terhadap produktivitas karyawan PT. Unggul Widya Teknologi Lestari Kabupaten Mamuju Utara.

Dari tabel 4.7 diatas bahwa besarnya probabilitas signifikansi variabel lingkungan kerja (X2) adalah 0,001 < taraf signifikan yang diisyaratkan $\alpha$ 0,05. Dengan demikian bahwa secara statistik variabel lingkungan kerja dalam penelitian ini memberikan pengaruh yang signifikan terhadap produktivitas karyawan PT. Unggul Widya Teknologi Lestari Kabupaten Mamuju Utara.

d. Pembuktian Hipotesis Keempat

Hipotesis ketiga yaitu untuk mengetahui apakah variabel penghasilan (X3), secara parsial berpengaruh signifikan terhadap produktivitas 
karyawan PT. Unggul Widya Teknologi Lestari Kabupaten Mamuju Utara.

Dari tabel 4.7 diatas bahwa besarnya probabilitas signifikansi variabel penghasilan (X3) adalah $0,000<$ taraf signifikan yang diisyaratkan $\alpha 0,05$. Dengan demikian bahwa secara statistik variabel tingkat penghasilan dalam penelitian ini memberikan pengaruh yang signifikan terhadap produktivitas karyawan PT. Unggul Widya Teknologi Lestari Kabupaten Mamuju Utara.

\section{Pembahasan}

Hasil pembuktian hipotesis dalam penelitian ini pengaruh sikap mental, lingkungan kerja, dan tingkat penghasilan terhadap produktivitas karyawan PT. Unggul Widya Teknologi Lestari Kabupaten Mamuju Utara memberikan pembuktian bahwa ketiga variabel independen yaitu sikap mental, lingkungan kerja, dan tingkat penghasilan memiliki pengaruh secara signifikan terhadap produktivitas kerja karyawan. Dengan demikian dinyatakan bahwa hipotesis mengenai pengaruh sikap mental, lingkungan kerja, dan tingkat penghasilan terhadap produktivitas karyawan PT. Unggul Widya Teknologi Lestari Kabupaten Mamuju Utara dapat diterima.

\section{Sikap Mental, Lingkungan Kerja, dan Penghasilan Berpengaruh Terhadap Produktivitas Karyawan PT. Unggul Widya Teknologi Lestari Kabupaten Mamuju Utara \\ Hasil penelitian membuktikan bahwa penelitian ini seluruh faktor independen berpengaruh positif terhadap Produktivitas Karyawan PT. Unggul Widya Teknologi Lestari Kabupaten Mamuju Utara artinya jika ketiga variabel tersebut diperlukan dalam waktu bersamaan, maka hal tersebut menimbulkan peningkatan Produktivitas Karyawan PT. Unggul Widya Teknologi Lestari Kabupaten Mamuju Utara.}

\section{Sikap Mental Berpengaruh Terhadap Produktivitas Karyawan PT. Unggul Widya Teknologi Lestari Kabupaten Mamuju Utara. Mekanisme mental yang mengevaluasi, membentuk pandangan, mewarnai perasaan dan akan ikut menentukan kecenderungan perilaku individu terhadap manusia lainnya atau sesuatu yang sedang dihadapi oleh individu, bahkan terhadap diri individu itu sendiri disebut fenomena sikap. Fenomena sikap yang timbul tidak saja ditentukan oleh keadaan objek yang sedang}

dihadapi tetapi juga dengan kaitannya dengan pengalaman-pengalaman masa lalu, oleh situasi di saat sekarang, dan oleh harapan-harapan untuk masa yang akan dating. Bagi karyawan yang mampu menjaga sikap yang baik dalam bekerja akan mencerminkan produktivitas kerja yang tinggi karena mampu bertangungjawab atas tugas yang diberikan oleh perusahaan.

Lingkungan Kerja Berpengaruh Terhadap Produktivitas Karyawan PT. Unggul Widya Teknologi Lestari Kabupaten Mamuju Utara

Lingkungan kerja merupakan keadaan sekitar tempat kerja baik secara fisik maupun non fisik yang dapat memberikan kesan yang menyenangkan, mengamankan, menentramkan, dan betah kerja. Lingkungan kerja dapat dibagi atas 2 (dua) jenis, yaitu: lingkungan kerja sosial, dan lingkungan kerja fisik. Lingkungan kerja sosial mencakup hubungan kerja yang terbina dalam perusahaan. Kita bekerja di dalam perusahaan tidaklah seorang diri, dan dalam melakukan aktivitas, kita juga membutuhkan bantuan orang lain. Dengan demikian kita wajib membina hubungan yang baik antara rekan kerja, bawahan maupun atasan karena kita saling membutuhkan. Hubungan kerja yang terbentuk sangat mempengaruhi psikologi karyawan. Komunikasi yang baik merupakan kunci untuk membangun hubungan kerja. Komunikasi yang buruk dapat menyebabkan kesalah-pahaman karena gagal menyampaikan pikiran dan perasaan satu sama lain. Komunikasi yang baik dapat digunakan sebagai alat untuk memotivasi kerja karyawan dan membangun tim kerja yang solid. Dengan lingkungan kerja yang baik tentunya akan terjadi peningkatan produktivitas kerja karyawan.

Penghasilan Berpengaruh Terhadap Produktivitas Karyawan PT. Unggul Widya Teknologi Lestari Kabupaten Mamuju Utara Penghasilan pada dasarnya merupakan balas jasa yang diterima pemilik faktor produksi atas pengorbannya dalam proses produksi. Tingkat pendapatan karyawan tentunya akan mempengaruhi semangat kerja karyawan dengan demikian akan berdampak pula pada produktivitas kerja karyawan. Dengan tingkat pendapatan yang tinggi akan menambah motivasi karyawan untuk bekerja lebih optimal dan memberikan kinerja terbaik untuk perusahaan sebagai timbal balik atas penghasilan yang diterima karyawan dari perusahaan. Dengan demikian dapat dikatakan 
bahwa tingkat pendapatan yang tinggi tentunya akan mampu meningkatkan produktivitas kerja karyawan.

\section{Kesimpulan}

Berdasarkan hasil analisis yang telah dilakukan maka dapat disimpulkan bahwa:

a. Sikap Mental, Lingkungan Kerja dan Penghasilan berpengaruh serempak terhadap Produktivitas Karyawan PT. Unggul Widya Teknologi Lestari Kabupaten Mamuju Utara

b. Sikap Mental, lingkungan kerja dan tingkat penghasilan berpengaruh terhadap Produktivitas Karyawan PT. Unggul Widya Teknologi Lestari Kabupaten Mamuju Utara

c. Variabel penghasilan merupakan variabel yang dominan berpengaruh terhadap produktivitas kerja karyawan PT. Unggul Widya Teknologi Lestari Kabupaten Mamuju Utara karena memiliki nilai signifikansi paling rendah yaitu 0,000 dan nilai Beta tertinggi yaitu 0,703 .

\section{Saran-Saran}

Berdasarkan kesimpulan yang di ambil, maka penulis memberikan saran sebagai berikut:

a. Pimpinan perusahaan harus memperhatikan lingkungan kerja dan tingkat pendapatan karyawan agar mampu meningkatkan produktivitas kerja karyawan pada perusahaan tersebut.

b. Pimpinan perusahaan harus selalu melakukan evaluasi produktivitas kerja karyawan agar tujuan perusahaan dapat tercapai secara efektif dan efisien.

\section{DAFTAR PUSTAKA}

Areb Dan Henri Tanjung, 2003, Manajemen Sumber Daya Manusia Universitas Trisakti.

Intanghina, 2008. Organisasi Dan Manajemen; Perilaku, Struktur, Proses. Erlangga, Jakarta

Kuncoro, Madrajat. 2004. Metode Riset Untuk Bisnis Dan Ekonomi.Jakarta : Pt Gramedia Pustaka.

Mathis And Jackson, 2006. Human Dan Employmanet. Terjemahan Anas Setyaningsih. Bpfe-Ugm Yogyakarta

Moeheriono, 2010 Dasar-Dasar Administrasi Dan Manadjemen Perusahaan, Mandar Maju, Bandung

Mulyanto Dan Sutapa Hardaya, 2009, Pengaruh Motivasi, Kepuasan Kerja Dan
Komitmen Organisasi Terhadap Kinerja Pegawai Pada Dinas Tenaga Kerja Dan Transmigrasi Provinsi Daerah Istimewa Yogjakarta, Vol 1, No 2.

Rivai, Veithzal. 2011, Manajemen Sumber Daya Manusia Untuk Perusahaan: Dari Teori Ke Praktik, Rajagrafindo Persada, Jakarta

Rahman, A. (2021). Pengaruh Hubungan Interpersonal, Lingkungan Kerja, Dan Kecerdasan Emosional Terhadap Kinerja Pegawai Pada Kantor Komisi Pemilihan Umum Daerah (Kpud) Kabupaten Parigi Moutong. Jurnal Ekonomi Trend, 7(1), 58-70.

Https://Doi.Org/10.31970/Trend.V7i1.17 3

Robbins Stephen P, 2002. Teori Organisasi: Struktur Desain Dan Aplikasi. Ahli Bahasa Yusuf Udaya. Jakarta: Arcan.

Sarwono, 2001. Penilaian Kinerja Dan Pengembangan Karyawan. Edisi Pertama, Bpfe, Yogyakarta

Schermerharn, 2003. Personel And Human Resource Management. Edition: Usa Santoso. 2001. Pengantar Manajemen

Sugiyono. 2009. Perilaku Organisasi. Jilid I Edisi 9, Pt. Indeks Kelompok Gramedia, Jakarta, 2010. Metode Penelitian Bisnis.Bandung: Alfabeta

Rahman, A. (2019). Pengaruh Hubungan Interpersonal, Lingkungan Kerja, Dan Kecerdasan Emosional Terhadap Kinerja Pegawai Pada Kantor Komisi Pemilihan Umum Daerah (Kpud) Kabupaten Parigi Moutong. Jurnal Ekonomi Trend, 7(1), 58-70.

Https://Doi.Org/10.31970/Trend.V7i1.17 3

Salim, F. U. (2019). Pengaruh Motivasi Dan Kompetensi Terhadap Kinerja Pegawai Negeri Sipil Sekretariat Dewan Perwakilan Rakyat Daerah (Dprd) Propinsi Sulawesi Tengah. Jurnal Ekonomi Trend, 7(2), 12-18. Https://Doi.Org/10.31970/Trend.V7i2.17 6

Umar A, M. (2019). Strategi Pemasaran Dalam Upaya Peningkatkan Volume Penjualan Perusahaan Comforta Palu. Jurnal Ekonomi Trend, 7(1), 27-40. Https://Doi.Org/10.31970/Trend.V7i1.17 
Winardi, 2001, Motivasi Dan Pemotivasian Dalm

Manajemen, Cetakan Ketiga, Raja

Grafindo Persada, Jakarta. 